Article

\title{
Cellulose Nanofiber Biotemplated Palladium Composite Aerogels
}

\author{
Fred J. Burpo ${ }^{1, *,+}$, Alexander N. Mitropoulos ${ }^{1,2,+}$, Enoch A. Nagelli ${ }^{1}$ (D) Jesse L. Palmer ${ }^{1}$, \\ Lauren A. Morris $^{3}{ }^{\text {(D) }}$, Madeline Y. Ryu ${ }^{1}$ and J. Kenneth Wickiser ${ }^{1}$ \\ 1 Department of Chemistry and Life Science, United States Military Academy, West Point, NY 10996, USA; \\ alex.mitropoulos@usma.edu (A.N.M.); enoch.nagelli@usma.edu (E.A.N.); jesse.palmer@usma.edu (J.L.P.); \\ madeline.ryu@usma.edu (M.Y.R.); john.wickiser@usma.edu (J.K.W.) \\ 2 Department of Mathematical Sciences, United States Military Academy, West Point, NY 10996, USA \\ 3 Armament Research, Development and Engineering Center, U.S. Army RDECOM-ARDEC, \\ Picatinny Arsenal, NJ 07806, USA; lauren.a.morris17.civ@mail.mil \\ * Correspondence: john.burpo@usma.edu; Tel.: +01-845-938-3900 \\ + These authors contributed equally.
}

Academic Editor: Brigitte Jamart-Grégoire

Received: 11 May 2018; Accepted: 7 June 2018; Published: 9 June 2018

\begin{abstract}
Noble metal aerogels offer a wide range of catalytic applications due to their high surface area and tunable porosity. Control over monolith shape, pore size, and nanofiber diameter is desired in order to optimize electronic conductivity and mechanical integrity for device applications. However, common aerogel synthesis techniques such as solvent mediated aggregation, linker molecules, sol-gel, hydrothermal, and carbothermal reduction are limited when using noble metal salts. Here, we present the synthesis of palladium aerogels using carboxymethyl cellulose nanofiber (CNF) biotemplates that provide control over aerogel shape, pore size, and conductivity. Biotemplate hydrogels were formed via covalent cross linking using 1-ethyl-3-(3-dimethylaminopropyl) carbodiimide hydrochloride (EDC) with a diamine linker between carboxymethylated cellulose nanofibers. Biotemplate CNF hydrogels were equilibrated in precursor palladium salt solutions, reduced with sodium borohydride, and rinsed with water followed by ethanol dehydration, and supercritical drying to produce freestanding aerogels. Scanning electron microscopy indicated three-dimensional nanowire structures, and X-ray diffractometry confirmed palladium and palladium hydride phases. Gas adsorption, impedance spectroscopy, and cyclic voltammetry were correlated to determine aerogel surface area. These self-supporting CNF-palladium aerogels demonstrate a simple synthesis scheme to control porosity, electrical conductivity, and mechanical robustness for catalytic, sensing, and energy applications.
\end{abstract}

Keywords: aerogels; palladium; porous; nanomaterials; catalysis

\section{Introduction}

Natural biomaterials display several examples of forming controlled structures with dimensions observed at the submicron and nanometer scales [1]. Recently, generating feature sizes at these length scales has been of interest using biopolymers such as proteins, carbohydrates, and nucleic acids because these molecules' innate structure can be controlled at nanometer dimensions in bulk materials due to natural self-assembly [1,2]. However, even though nature uses these molecules at nano-dimensions, engineering new structures with the same materials at these length scales is challenging as the current technology in micro and nanofabrication, such as lithography or e-beam writing are not easily compatible with biomaterials [2,3]. Chemical vapor deposition (CVD) has been shown to produce exact 
replicas of biological specimens as templates leave the underlying structure unharmed [4]. However, CVD requires expensive equipment and control to accurately template biostructures. Additionally, current micro- and nanofabrication methods generally produce thin-film structures and do not allow for easy formation of bulk nanostructured three-dimensional networks [2,5]. A synthesis route for assembling bulk nanostructures relies on the natural self-assembly of biomaterials such as cellulose, which use intrinsic molecular interactions to produce hierarchical nano-networks, while offering flexibility and biocompatibility, making these materials ideal to be used as templates [6,7].

Cellulose is the most abundant natural polymer and primary structural component found in cell walls and the components of wood known for its strength and flexibility [8-11]. Made from a linear chain of $\beta(1 \rightarrow 4)$ D-glucose molecules, cellulose functions as an energy storage and structural molecule found primarily in the cell wall of many plants and bacteria [8]. However, the properties of cellulose can be engineered by processing individual cellulose molecules into nanocrystalline structures to generate cellulose nanofibers (CNFs), a form of cellulose where several molecules assemble together to form fibers with a high aspect ratio approximately 20 nanometers in diameter and hundreds of nanometers to several microns in length [12-17]. Additionally, to improve the function and capacity of CNFs, cellulose can be modified with carboxymethyl groups to enhance gelation and ionic conjugation giving CNFs additional properties [18-20].

Nanocellulose and CNFs have interested researchers over the last few decades because they offer the strength and flexibility of cellulose with dimensions that can be used to produce films and hydrogels that are stronger than cellulose in its innate form [21-24]. Additionally, CNFs are water soluble and renewable materials that do not require harsh organic solvents or drastic changes in $\mathrm{pH}$ to process $[12,25]$. The hydroxyl group found in cellulose can be functionalized with a carboxymethyl group facilitating CNFs to form freestanding gels with high porosity and large surface area [26-29]. Therefore, optimizing the concentration can generate robust hydrogels with high porosity, and allow $\mathrm{CNFs}$ to act as a biotemplate for the electrochemical deposition of metals. In their hydrated state, carboxymethyl CNF hydrogels can electrostatically bind metal cations that attach to negatively charged functional groups adding increased flexibility to this material platform [6,7,30-34].

Noble metal salts easily form nanoparticles with common reducing agents in numerous synthesis methods. Nobel metal aerogels have been formed via sol-gel, solvent mediated aggregation, select alloy etching, linker molecules, and direct reduction [35-39]. Additionally, three-dimensional nanostructures have been achieved using biotemplating with noble metal salts binding to oppositely charged template surfaces. In this manner, charge distribution along biopolymer chains allows the metal salts to be deposited where the polymer acts as a structural template making a composite material [40-42]. Upon reduction with reducing agents such as sodium borohydride, biotemplates are metalized to make them conductive $[39,43]$. CNF hydrogels incubated in noble metals salts and chemically reduced can produce discrete templated nanoparticles along the CNF surface with the flexibility and mechanical properties of cellulose [31,32]. Maintaining the high porosity of CNF hydrogel biotemplated metal structure can be accomplished by supercritically drying with $\mathrm{CO}_{2}$ generating composite CNF aerogels $[26,44,45]$. Through this process, an insulating biopolymer becomes conductive via metallization providing unique opportunities to electrically, chemically, or optically functionalize these materials.

Here, we demonstrate a method to use covalently cross-linked carboxymethylated cellulose nanofibers as a nanostructured template network to form three-dimensional CNF-palladium composite aerogels. Equilibration of CNF hydrogels in palladium salt solutions allows for electrostatic binding of palladium ions onto the carboxylic acid functional groups on the biotemplate cellulose nanofibers. The high surface area and porosity associated with the CNF hydrogel confers similar properties to the metalized aerogel. Reduced with sodium borohydride and then supercritically dried, these CNF aerogels combine the unique physical and mechanical properties of cellulose with the conductivity of noble metals giving them potential as advanced energy, catalysis, and sensing platforms. 


\section{Materials and Methods}

\subsection{Hydrogel Preparation}

Carboxymethyl cellulose nanofibers (CNF) (University of Maine, Process Development Center, Orono, ME, USA) with a nominal $300 \mathrm{~nm}$ length and carboxymethyl concentration of $1.2 \mathrm{mmol} / \mathrm{g}$ were used to prepare hydrogels. CNF hydrogels were prepared from $3 \%(w / w)$ CNF solution in deionized water. In addition, $0.25 \mathrm{~mL}$ of the CNF solution was centrifuged for $20 \mathrm{~min}$ at $21,000 \times g$ that increased the CNF concentration to $3.8 \%(w / w)$. Solutions presented a translucent white color after centrifugation. CNF hydrogels were crosslinked in $0.5 \mathrm{M}$ 1-ethyl-3-(3-dimethylaminopropyl) carbodiimide hydrochloride (EDC) (Sigma Aldrich, Allentown, PA, USA) with 0.1 M MES buffer (Sigma Aldrich, Allentown, PA, USA), 0.25 M ethylenediamine (EDA) (Sigma Aldrich, USA) at pH 4.5 for $48 \mathrm{~h}$. Samples were rinsed in deionized water for $24 \mathrm{~h}$ before equilibrating the CNF hydrogels with 1, 10, 50, 100, 500, and $1000 \mathrm{mM}$ concentrations of either sodium tetrachloropalladate (II), or tetraamminepalladium (II) chloride (Sigma Aldrich, Allentown, PA, USA) for $24 \mathrm{~h}$. Samples were reduced in 2.0 M sodium borohydride, $\mathrm{NaBH}_{4}$, for $24 \mathrm{~h}$ followed by $0.5 \mathrm{M} \mathrm{NaBH}_{4}$ (Sigma Aldrich, Allentown, PA, USA) for $12 \mathrm{~h}$. Palladium composite gels were rinsed in deionized water for $24 \mathrm{~h}$. To maintain the palladium coated nanofibrillar hydrogel network, samples were then dehydrated in a series of ethanol rinses at concentrations of $25,50,75$, and 100\% $(v / v)$ in deionized water for $30 \mathrm{~min}$ each and then supercritically dried in $\mathrm{CO}_{2}$ using a Leica EM CPD300 Automated Critical Point Dryer (Leica Biosystems, Buffalo Grove, IL, USA) with a set point of $35^{\circ} \mathrm{C}$ and $1200 \mathrm{psi}$.

\subsection{Scanning Electron Microscopy}

Scanning electron microscopy (SEM) was used to evaluate scaffold morphology. All micrographs were taken with a FEI Helios 600 scanning electron microscope (ThermoFisher Scientific, Hillsboro, OR, USA). Samples were coated with gold for $30 \mathrm{~s}$ using a Desk V Denton sputter coater (Denton Vacuum, Moorestown, NJ, USA).

\subsection{Thermal Gravimetric Analysis (TGA)}

Thermal gravimetric analysis (TGA) was performed on a Thermal Instruments Q-500 (Thermal Instruments, New Castle, DE, USA) in a ramp state with a temperature rate of $10{ }^{\circ} \mathrm{C} / \mathrm{min}$ from ambient to $700{ }^{\circ} \mathrm{C}$. Samples were in nitrogen gas with a flow rate of $60 \mathrm{~mL} / \mathrm{min}$.

\subsection{X-Ray Diffractometry}

X-ray diffractometry (XRD) was performed with a PANalytical Emperean diffractometer (Malvern PANalytical, Almelo, the Netherlands). XRD scans for diffraction angles (2 $\theta)$ from $5^{\circ}$ to $90^{\circ}$ were performed at $45 \mathrm{kV}$ and $40 \mathrm{~mA}$ with $\mathrm{Cu} \mathrm{K} \alpha$ radiation $\left(1.54060 \AA\right.$ ) , a $2 \theta$ step size of $0.0130^{\circ}$, and $20 \mathrm{~s}$ per step. XRD spectra analysis was performed with High Score Plus software (Version 4.6, Malvern PANalytical, Almelo, the Netherlands).

\subsection{BET Analysis}

Adsorption-desorption measurements were performed according to IUPAC standards [46] using a Quantachrome NOVA 4000e (Quantachrome Instruments, Boynton Beach, FL, USA) surface area and pore size analyzer with nitrogen $\left(-196^{\circ} \mathrm{C}\right)$ as the test gas. All samples were vacuum degassed at room temperature for $24 \mathrm{~h}$ prior to measurement. Brunauer-Emmett-Teller (BET) analysis [47] was used to determine the specific surface area from gas adsorption. Pore-size distributions for each sample were calculated using the Barrett-Joyner-Halenda $(\mathrm{BJH})$ model [48] applied to volumetric desorption isotherms. All calculations were performed using Quantachrome's NovaWin software (Version 11.04, Quantachrome Instruments, Boynton Beach, FL, USA). 


\subsection{Electrochemical Characterization}

A Bio-Logic VMP-3 potentiostat was used to perform electrochemical impedance spectroscopy (EIS) and cyclic voltammetry (CV) (BioLogic Science Instruments, Knoxville, TN, USA). A three electrode cell was used with an $\mathrm{Ag} / \mathrm{AgCl}$ reference electrode, a $1 \mathrm{~mm}$ platinum wire counter-electrode, and a lacquer coated $1 \mathrm{~mm}$ platinum wire with exposed tip in contact with samples. In addition, $0.5 \mathrm{M}$ $\mathrm{H}_{2} \mathrm{SO}_{4}$ electrolyte was used for EIS and CV. EIS was performed at open circuit voltage with a frequency range of $1 \mathrm{MHz}$ to $1 \mathrm{mHz}$ with a $10 \mathrm{mV}$ sine wave. $\mathrm{CV}$ was performed in a voltage range of -0.2 to $1.2 \mathrm{~V}$ (vs. $\mathrm{Ag} / \mathrm{AgCl}$ ) with scan rates of $1,5,10,25,50,75$, and $100 \mathrm{mV} / \mathrm{s}$.

\section{Results and Discussion}

\subsection{Aerogel Synthesis}

Figure 1 depicts the synthesis scheme for cellulose nanofiber (CNF) palladium composite aerogels. Commercially available carboxymethylated CNFs were used in order to control the biotemplate surface charge by tuning the $\mathrm{pH}$, and consequently the deprotonation of the carboxyl groups. At $\mathrm{pH}$ values lower than the carboxyl groups' $\mathrm{pKa}$ of approximately 4.34 , the negatively charged carboxylate groups serve as electrostatic binding sites for positively charged metal cations [49]. CNF hydrogels were prepared by centrifuging CNF solutions to ensure overlap of the cellulose nanofibers forming a physically entangled gel. Figure 1a depicts 1-ethyl-3-(3-dimethylaminopropyl) carbodiimide hydrochloride (EDC) with an ethylenediamine linker diffused into the compacted CNF gel. EDC molecules form an amide bond between one of the carboxyl groups on the cellulose nanofibers and one amine group on the ethylenediamine molecule. The second amine on ethylenediamine is then available to form a second amide linkage with an adjacent CNF through the coupling with another EDC molecule. In this manner, the carboxymethyl cellulose nanofibers are covalently linked to improve structural stability as shown in Figure 1b,c [50]. The resulting covalent hydrogels are then equilibrated in palladium salts solutions (Figure 1d), and then immersed in $\mathrm{NaBH}_{4}$ solution to reduce palladium ions within the gel. The metalized CNF-Pd composite gel is rinsed, solvent exchanged with ethanol, and supercritically dried to yield a CNF-Pd composite aerogel depicted in Figure 1e.

(a)

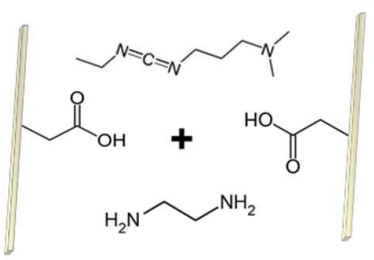

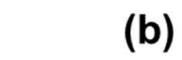

(b)

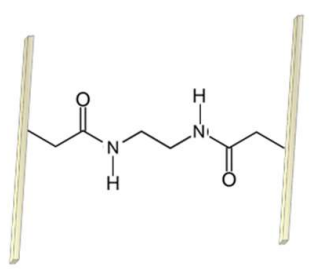

(c)

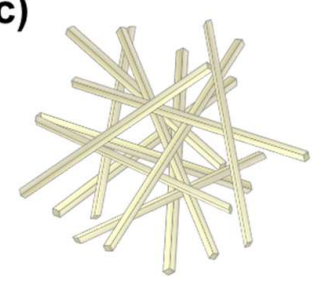

(d)

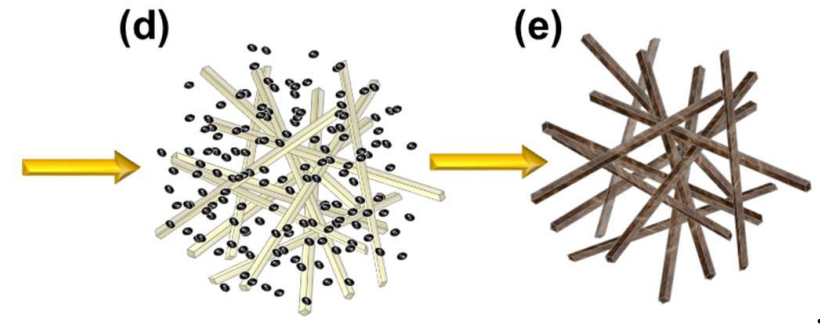

Figure 1. Aerogel synthesis scheme. (a) cross linking carboxymethyl cellulose nanofibers (CNF) with EDC and ethylenediamine as a linker molecule; (b),(c) cross-linked carboxymethyl cellulose nanofibers; (d) CNF hydrogel equilibrated with palladium salt solution; (e) CNF biotemplated palladium composite aerogel after reduction with $\mathrm{NaBH}_{4}$, rinsing, solvent exchange with ethanol, and supercritical drying.

Figure 2 shows photo images of the synthesis scheme depicted in Figure 1 from covalent hydrogel formation through supercritical drying. Cellulose hydrogels shown in Figure 2a were 
crosslinked in microfuge tubes after compaction with centrifugation and then rinsed in deinionized water. After rinsing, CNF hydrogels were equilibrated in palladium salt solution with concentrations of $1,10,50,100,500$, and $1000 \mathrm{mM}$. Both $\mathrm{Pd}\left(\mathrm{NH}_{3}\right)_{4} \mathrm{Cl}_{2}$ (Figure $2 \mathrm{~b}$ ) and $\mathrm{Na}_{2} \mathrm{PdCl}_{4}$ (Figure 2c) salt solutions, with corresponding complex ions of $\left[\mathrm{Pd}\left(\mathrm{NH}_{3}\right)_{4}\right]^{2+}$ and $\left[\mathrm{PdCl}_{4}\right]^{2-}$ were used with the synthesis scheme in Figure 1 . The negatively charged $\left[\mathrm{PdCl}_{4}\right]^{2-}$ ion exhibits a brown color correlating to the equilibrated ion concentration, whereas the pale yellow color of $\left[\mathrm{Pd}\left(\mathrm{NH}_{3}\right)_{4}\right]^{2+}$ exhibits a less pronounced color correlation with concentration. Despite the osmotic pressures experienced by the CNF hydrogels solvated in water and exposed to increasing concentrations of palladium salt solutions up to $1000 \mathrm{mM}$, no gel swelling or de-swelling was observed for gels covalently cross-linked with EDC. In the absence of EDC mediated covalent cross-linking, physically entangled CNF hydrogels swelled and disaggregated in the presence of salt solutions, indicating increased gel stability with covalent cross-linking.

Hydrogels equilibrated in palladium solution were then reduced in $2.0 \mathrm{M} \mathrm{NaBH}_{4}$ to form CNF-Pd composite gels. Exposure to such a high reducing agent concentration resulted in violent hydrogen gas evolution as a by-product of the electrochemical reduction; however, Figure $2 \mathrm{~d}$ demonstrates that gels remained intact after reduction. Gels prepared with palladium solutions equal or greater to $50 \mathrm{mM}$ were dark black, while gels using $10 \mathrm{mM}$ and $1 \mathrm{mM}$ palladium solutions were slightly translucent. Gels were then rinsed in deionized water for at least $24 \mathrm{~h}$ to ensure that all excess reducing agent solution was removed from the CNF-Pd composite gel before solvent exchange to dehydrate the sample with ethanol. The dehydrated gels were then supercritically dried and are shown in Figure $2 \mathrm{e}$. Reduced gels before and after supercritical drying presented an equivalent macroscopic appearance for gels prepared with both $\left[\mathrm{PdCl}_{4}\right]^{2-}$ and $\left[\mathrm{Pd}\left(\mathrm{NH}_{3}\right)_{4}\right]^{2+}$ solutions.

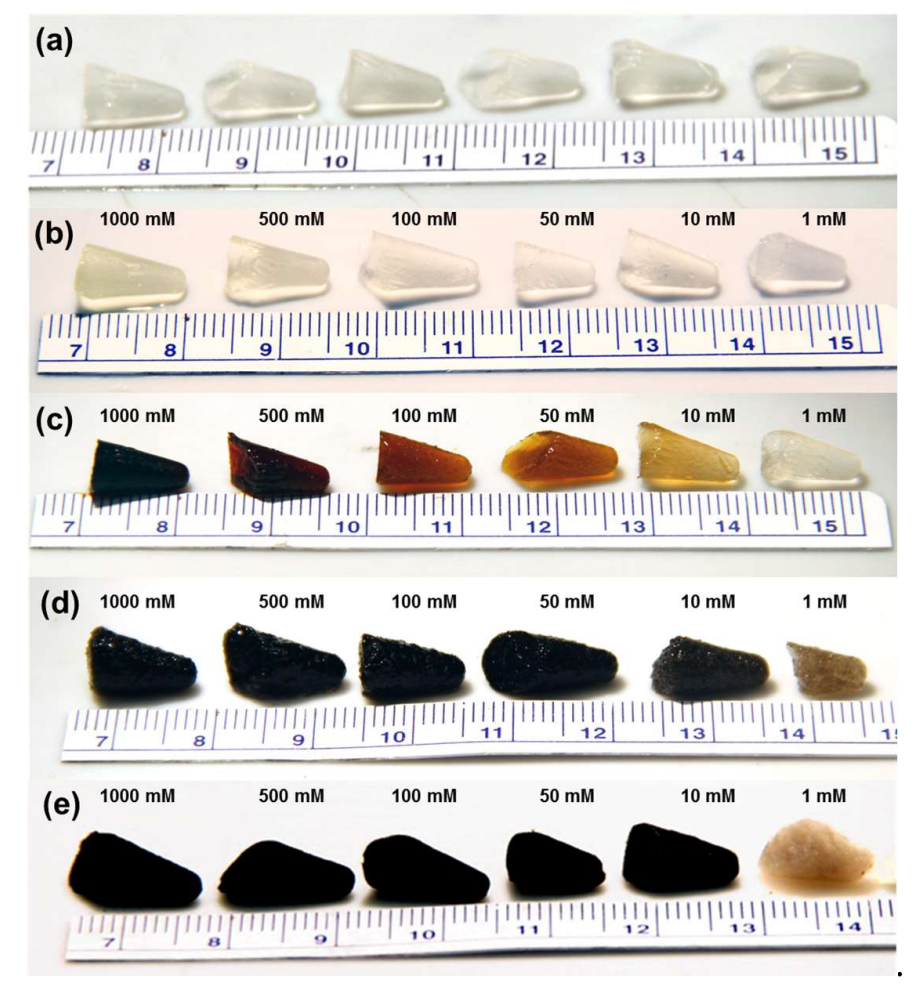

Figure 2. Aerogel synthesis process photos. (a) cross linked carboxymethyl cellulose nanofiber hydrogels with EDC and ethylenediamine as a linker molecule. CNF hydrogels equilibrated with palladium salt solutions of $1,10,50,100,500$, and $1000 \mathrm{mM}$ for (b) $\mathrm{Pd}\left(\mathrm{NH}_{3}\right)_{4} \mathrm{Cl}_{2}$, and (c) $\mathrm{Na}_{2} \mathrm{PdCl}_{4}$; (d) CNF biotemplated palladium aerogel after reduction with $\mathrm{NaBH}_{4}$; (e) $\mathrm{CNF}-\mathrm{Pd}$ composite aerogels after rinsing, solvent exchange with ethanol and supercritical drying. 


\subsection{Scanning Electron Microscopy}

Figure 3 shows scanning electron micrographs of CNF-Pd composite aerogels prepared using 1, $10,50,100,500$, and $1000 \mathrm{mM} \mathrm{Pd}\left(\mathrm{NH}_{3}\right)_{4} \mathrm{Cl}_{2}$. For aerogels prepared with $1 \mathrm{mM}$ palladium solutions (Figure 3a), resulting aerogels present interconnected fibrillar elements with an average diameter of $12.6 \pm 2.2 \mathrm{~nm}$ and pore sizes of $32.4 \pm 13.3 \mathrm{~nm}$, and a diameter of $12.4 \pm 2.0 \mathrm{~nm}$ and pore size of $32.2 \pm 10.4 \mathrm{~nm}$ for $10 \mathrm{mM}$ samples (Figure $3 \mathrm{~b}$ ). For aerogels prepared with palladium concentrations of $50 \mathrm{mM}$ and above (Figure 3c-f), the nanostructure changes compared to the lower concentrations to exhibit more pronounced interconnected nanoparticles. For the 50, 100, 500, and $1000 \mathrm{mM}$ palladium synthesis concentrations, the average nanoparticle diameters are: $19.5 \pm 5.0 \mathrm{~nm}, 41.9 \pm 10.0 \mathrm{~nm}$, $45.6 \pm 14.6 \mathrm{~nm}$, and $59.0 \pm 16.4 \mathrm{~nm}$. The nanoparticle size generally correlates with the equilibrated palladium precursor solution.

The observed nanostructure is similar to palladium and platinum structures synthesized using a direct reduction method using the same reagents at $100 \mathrm{mM}$ concentrations in the absence of biotemplate [39]. Whereas the previously reported direct reduction method relies on hydrogen gas evolution for the coalescence of nanoparticles to form an aerogel monolith, it lacks macroscopic shape control compared to the method presented here with a defined shape biotemplate. The presence of the CNF aerogel not only guides the macroscopic monolith shape, but also serves as an anchor for nanoparticle attachment. We propose that the formation of the nanostructures occurs via palladium cations, $\left[\mathrm{Pd}\left(\mathrm{NH}_{3}\right)_{4}\right]^{2+}$, electrostatically bound to deprotonated carboxyl $\left(\mathrm{COO}^{-}\right)$groups reduced to form initial nanoparticles along the surface of the cellulose nanofibers, allowing for fusion of nanoparticles formed within the hydrogel pores through surface free energy minimization. In the absence of crosslinking, ionic gels formed by centrifuging CNF solutions in the presence of palladium salt solutions, and reduced with $\mathrm{NaBH}_{4}$ resulted in nanofoams that did not maintain their macroscopic shape (Figure S1).
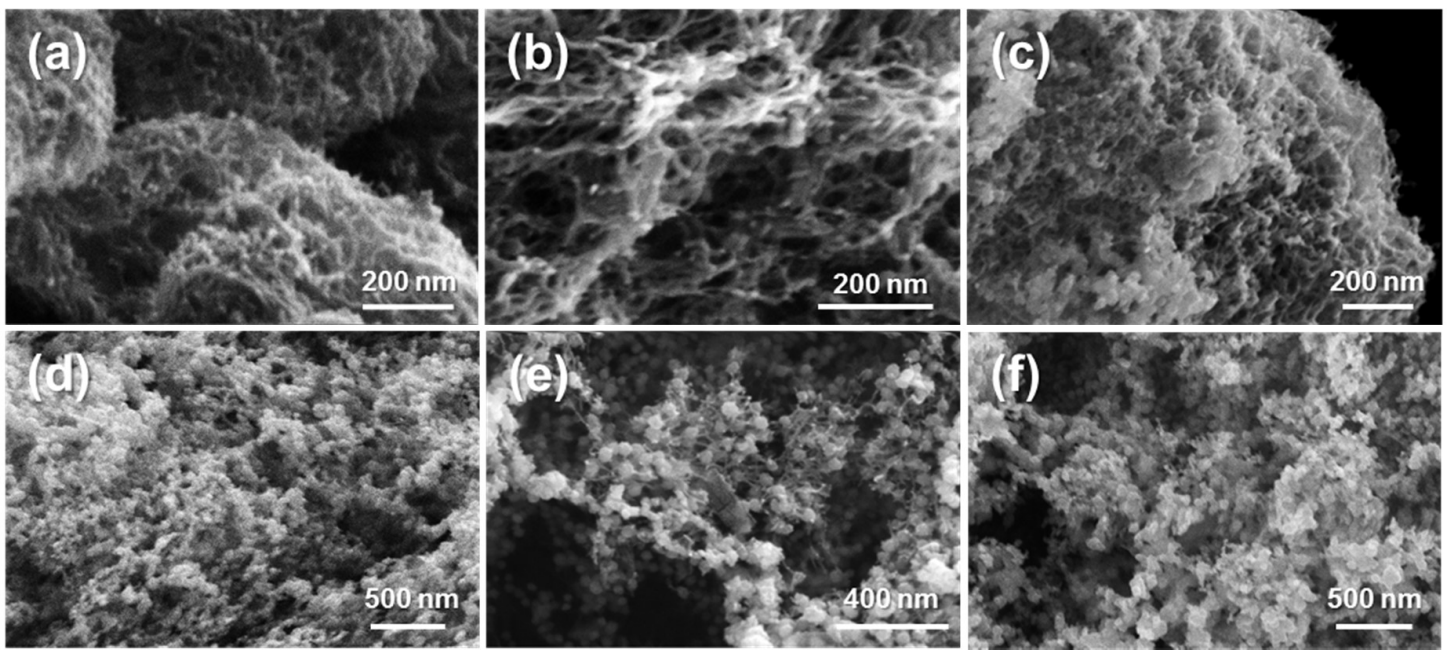

Figure 3. Scanning electron microscopy images of CNF-Pd composite aerogels prepared from $\mathrm{Pd}\left(\mathrm{NH}_{3}\right)_{4} \mathrm{Cl}_{2}$ concentrations of (a) $1 \mathrm{mM}$; (b) $10 \mathrm{mM}$; (c) $50 \mathrm{mM}$; (d) $100 \mathrm{mM}$; (e) $500 \mathrm{mM}$; and (f) $1000 \mathrm{mM}$.

\subsection{X-Ray Diffractometry}

Figure 4 shows the $X$-ray diffraction spectra for CNF-Pd composite aerogels synthesized with 1 , $10,50,100,500$, and $1000 \mathrm{mM} \mathrm{Pd}\left(\mathrm{NH}_{3}\right)_{4} \mathrm{Cl}_{2}$. For the lower synthesis concentrations and consequent lower metal to organic mass ratio, the XRD signal-to-noise ratio is low, but increases for aerogels prepared with $500 \mathrm{mM}$ and $1000 \mathrm{mM}$ palladium salt solutions. Spectra peak positions for all synthesis concentrations are broad indicating small crystallite sizes, and did not index to a single phase of 
palladium. For aerogels prepared with palladium solutions $100 \mathrm{mM}$ and below, the presence of $\mathrm{PdH}_{0.706}$ palladium hydride peaks, indexed to Joint Committee on Powder Diffraction Standards (JCPDS) reference number 00-018-0951, were distinctly seen at $38.7^{\circ}, 45.0^{\circ}, 65.6^{\circ}$, and $78.9^{\circ}$ for the (111), (200), (220), and (311) Miller indices, respectively. At room temperature, palladium hydride may exist in an $\alpha$ and $\beta$ phase, where the hydrogen to palladium ratio for $\alpha$ phase is 0.03 , and approximately 0.6 for the $\beta$ phase [51]. The presence of the palladium hydride phase suggests that during the electrochemical reduction with $\mathrm{NaBH}_{4}$ hydrogen gas is entrained within the palladium nanoparticles [51]. With a $2.0 \mathrm{M}$ $\mathrm{NaBH}_{4}$ reducing agent, hydrogen gas evolution within the CNF hydrogel pores is thought to generate sufficient gas pressure to drive the formation of the palladium hydride phase. The palladium phase in the aerogels was indexed to JCPDS reference 01-087-0643. Like palladium hydride, the palladium phase has a cubic crystal system, and a Fm-3m space group. As the palladium synthesis concentrations increase from $1 \mathrm{mM}$ to $1000 \mathrm{mM}$, the distinct palladium hydride peaks become convoluted with the palladium phase peaks, such that they are not distinguishable at $1000 \mathrm{mM}$. Peak broadening decreases as the palladium synthesis concentrations increase corresponding to the average fiber diameters determined from SEM images in Figure 3. At $1 \mathrm{mM}$, the (111) and (200) peaks are combined and very broad, resolving as distinguishable peaks at synthesis concentrations above $100 \mathrm{mM}$. Similar XRD spectra were achieved for aerogels prepared using $\mathrm{Na}_{2} \mathrm{PdCl}_{4}$ (Figure S2).

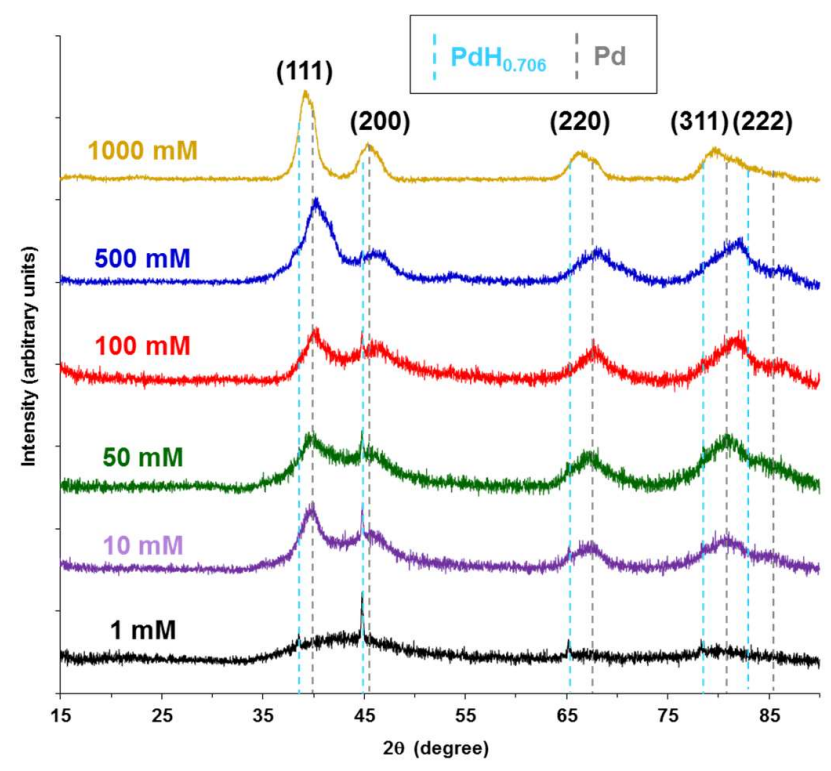

Figure 4. X-ray diffraction spectra for CNF-Pd composite aerogels synthesized from $\mathrm{Pd}\left(\mathrm{NH}_{3}\right)_{4} \mathrm{Cl}_{2}$ salt solution concentrations of $1 \mathrm{mM}, 10 \mathrm{mM}, 50 \mathrm{mM}, 100 \mathrm{mM}, 500 \mathrm{mM}$, and $1000 \mathrm{mM}$. JCPDS reference 00-018-0951 palladium hydride peak positions are indicated with a light blue dashed line, and dashed gray lines for 01-087-0643 palladium peak positions.

\subsection{Thermalgravimetric Analysis (TGA)}

To characterize the ratio of palladium and CNFs in the composite aerogels synthesized using $\operatorname{Pd}\left(\mathrm{NH}_{3}\right)_{4} \mathrm{Cl}_{2}$, thermogravimetric analysis (TGA) was performed with results shown in Figure 5. TGA revealed higher weight percentages of palladium in CNF-Pd composite aerogels synthesized from hydrogels equilibrated with higher concentration palladium solutions. Cellulose decomposes beyond $300{ }^{\circ} \mathrm{C}$, as observed in the change in curve shape analyzed by the derivative weight shown in Figure 5a,b [52]. After complete decomposition of the CNF network, the remaining mass at $600{ }^{\circ} \mathrm{C}$ is the reduced palladium (Figure 5c). Similar results were achieved for aerogels prepared using $\mathrm{Na}_{2} \mathrm{PdCl}_{4}$ (Figure S3). The resulting metal to CNF mass ratios range from 0.002 to 3.1 , and $0.07 \%$ to $75.5 \%$ for 1 $\mathrm{mM}$ to $1000 \mathrm{mM}$, respectively (Figure 5c). 

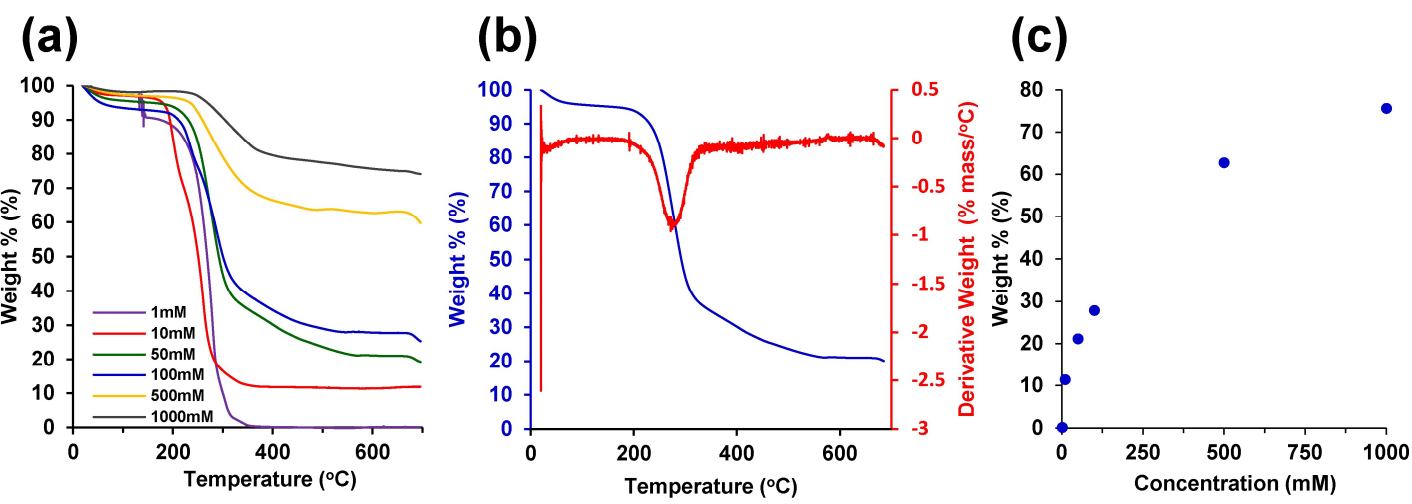

Figure 5. Thermogravimetric analysis (TGA). (a) TGA of aerogels synthesized with $\mathrm{Pd}\left(\mathrm{NH}_{3}\right)_{4} \mathrm{Cl}_{2}$ salt solutions; (b) TGA of $50 \mathrm{mM} \mathrm{Pd}\left(\mathrm{NH}_{3}\right)_{4} \mathrm{Cl}_{2}$ sample from (a) with differential thermal analysis (DTA); (c) palladium sample mass at $600{ }^{\circ} \mathrm{C}$ from (a) for the varying palladium concentrations.

\subsection{Nitrogen Gas Adsorption}

Nitrogen gas adsorption isotherms were generated for CNF-Pd aerogels prepared with $0 \mathrm{mM}$, $100 \mathrm{mM}$, and $1000 \mathrm{mM} \mathrm{Pd}\left(\mathrm{NH}_{3}\right)_{4} \mathrm{Cl}_{2}$. The BET specific surface area of the $0 \mathrm{mM}, 100 \mathrm{mM}$, and $1000 \mathrm{mM}$ samples was 582,456 , and $171 \mathrm{~m}^{2} / \mathrm{g}$, respectively, indicating that the specific surface area decreases in aerogels equilibrated with increasing concentration of palladium salt. The physisorption data shown in Figure 6 illustrates type IV adsorption-desorption isotherms in accordance with the IUPAC classification standards, revealing both mesoporous (2-50 $\mathrm{nm}$ in diameter) and macroporous (> $50 \mathrm{~nm}$ in diameter) structures in the CNF and CNF-Pd composite aerogel samples. The nitrogen adsorption quantity rises sharply for all samples at high relative pressures and no limiting adsorption is observed, consistent with the presence of both mesopores and macropores [47]. At relative pressure $\mathrm{P} / \mathrm{P}_{0}=0.995$, the maximum volume adsorbed for the $0 \mathrm{mM}, 100 \mathrm{mM}$, and $1000 \mathrm{mM}$ samples was 4512,3653 , and $1372 \mathrm{~cm}^{3} / \mathrm{g}$, respectively. H3 type hysteresis is observed in all samples, characteristic of capillary condensation in the mesopores. The hysteresis closes at higher relative pressures for increasing Pd concentrations as compared to the $0 \mathrm{mM}$ sample, indicating that the smaller mesopores $(<30 \mathrm{~nm})$ are eliminated by the increasing addition of the Pd phase; this result is consistent with the Barrett-Joyner-Halenda (BJH) pore size analysis, which shows a decreasing frequency of mesopores with the increasing addition of Pd [48]. The increasing blockage of mesopores with higher concentrations of palladium salt is evident in the pore volume distribution curves and is consistent with the observed reduction in specific surface area. BJH analysis of the desorption curve shows that the cumulative pore volume for the $0 \mathrm{mM}, 100 \mathrm{mM}$, and $1000 \mathrm{mM}$ samples was 7.171, 5.801, and $2.171 \mathrm{~cm}^{3} / \mathrm{g}$, respectively. For CNF hydrogels with fixed pore sizes via covalent crosslinking, the reduction of higher Pd ion concentration results in increased metal content within the pores, and consequently the decreased cumulative pore volume observed with $\mathrm{BJH}$ analysis.

Sample porosities were calculated for the $0 \mathrm{mM}, 100 \mathrm{mM}$, and $1000 \mathrm{mM}$ aerogel samples from Equation (1):

$$
\% \text { Porosity }=\left(\mathrm{V}_{\text {pores }} / \mathrm{V}_{\text {sample }}\right) \times 100 \% \text {, }
$$

with $\mathrm{V}_{\text {pores }}$ and $\mathrm{V}_{\text {sample }}$ as total pore and bulk sample volumes, respectively. The average bulk sample volumes of the $0 \mathrm{mM}, 100 \mathrm{mM}$ and $1000 \mathrm{mM}$ samples were determined by measuring the volume and weight of three of each of the samples and calculating the average value. The resulting sample specific volumes for the $0 \mathrm{mM}, 100 \mathrm{mM}$, and $1000 \mathrm{mM}$ samples were $7.37 \mathrm{~cm}^{3} / \mathrm{g}, 6.10 \mathrm{~cm}^{3} / \mathrm{g}$, and $2.40 \mathrm{~cm}^{3} / \mathrm{g}$, respectively. The corresponding pore volumes were taken from the cumulative pore volume from the gas adsorption data. The resulting porosities for the $0 \mathrm{mM}, 100 \mathrm{mM}$, and $1000 \mathrm{mM}$ samples were $97.3 \%, 95.0 \%$, and $90.4 \%$. 

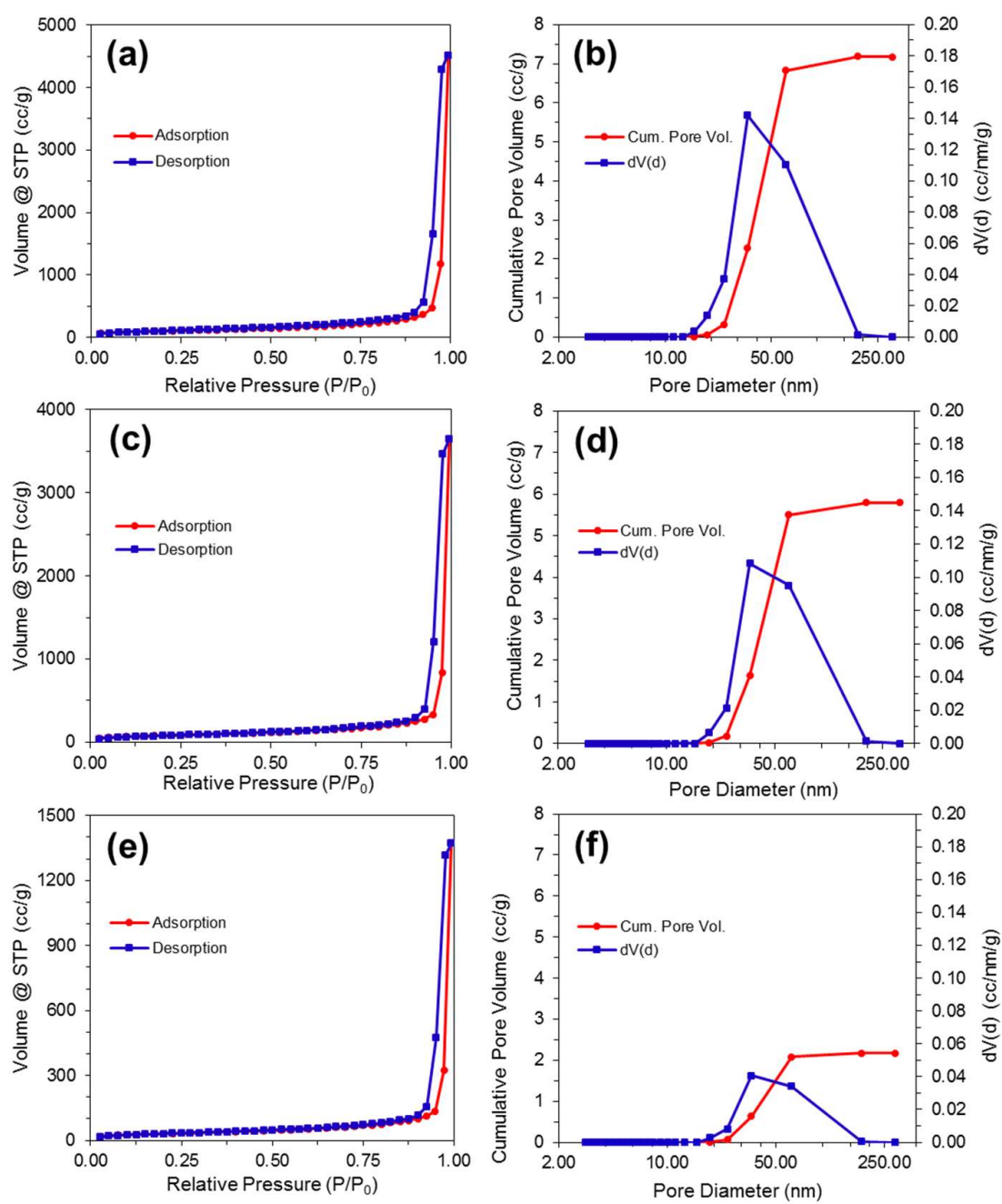

Figure 6. BET analysis. Nitrogen adsorption-desorption isotherms, and pore size distribution with cumulative pore volume for aerogels synthesized with palladium $\mathrm{Pd}\left(\mathrm{NH}_{3}\right)_{4} \mathrm{Cl}_{2}$ salt solutions of (a,b) $0 \mathrm{mM} ;(\mathbf{c}, \mathbf{d}) 100 \mathrm{mM} ;(\mathbf{e}, \mathbf{f}) 1000 \mathrm{mM}$.

\subsection{Electrochemical Characterization}

The electrochemical analysis using CV and EIS techniques is shown in Figure 7. The Nyquist plot from $140 \mathrm{kHz}$ to $15 \mathrm{mHz}$ depicted in Figure 7a,b shows an incomplete semi-circle in the high frequency region indicating low resistance to charge transfer and double layer capacitance in the electrode/electrolyte interface. During the transition from high scan frequencies to low frequencies, there is a deviation from ideal capacitive behavior as the slope of the line starts to decrease toward the real axis due to non-ideal double layer capacitance from the non-uniform current distribution through the aerogel network, likely due to the composite mixture of metal and organic phases in the aerogels. The specific capacitance from the EIS plot at $15 \mathrm{mHz}$ in Figure 7 a was determined to be $40.6 \mathrm{mF} / \mathrm{g}$ using the relation:

$$
\mathrm{C}_{\mathrm{sp}}=1 /\left(2 \pi \mathrm{Z}^{\prime \prime} f \mathrm{~m}\right),
$$

with $f$ as the frequency, $Z$ " as the impedance imaginary component, and $m$ as the sample palladium mass. A transmission line equivalent circuit model developed for porous noble metal aerogels was fit to the Nyquist plot in Figure 7a [39]. The transmission line model and resultant Nyquist plot model fit in Figure S5 are based on a modified Randles circuit consisting of parallel and serially connected resistors, constant phase elements or a capacitors, and restrictive diffusion elements through the hierarchical porous biotemplate aerogel network [53-55]. 
The CV scans at 10, 25, 50, and $75 \mathrm{mV} / \mathrm{s}$ in $0.5 \mathrm{M} \mathrm{H}_{2} \mathrm{SO}_{4}$ electrolyte shown in Figure 7c exhibit characteristic hydrogen adsorption-desorption, and the redox peaks associated with palladium. The $\mathrm{CV}$ scan at $10 \mathrm{mV} / \mathrm{s}$ in Figure $7 \mathrm{~d}$ clearly shows the defined current response resulting from hydrogen adsorption and desorption peaks between $-0.2 \mathrm{~V}$ and $0 \mathrm{~V}$ (vs. $\mathrm{Ag} / \mathrm{AgCl}$ ), along with palladium oxidation-reduction peaks more positive than $+0.5 \mathrm{~V}$. The predominant capacitive region between +0.1 and $+0.3 \mathrm{~V}$ (vs. $\mathrm{Ag} / \mathrm{AgCl}$ ) yields a specific capacitance for the metal content of the aerogel of $34.7 \mathrm{mF} / \mathrm{g}$, which is similar to the value determined from EIS.

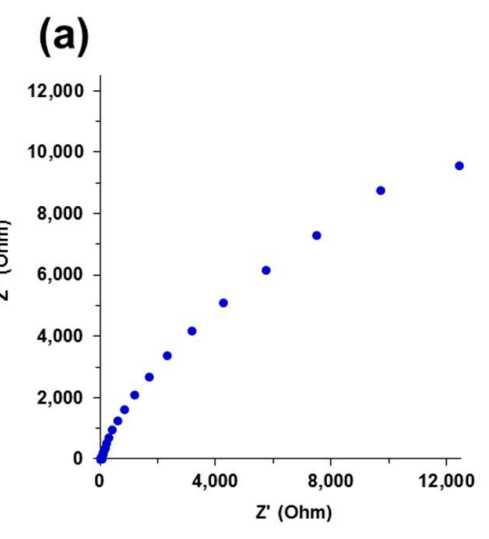

(c)

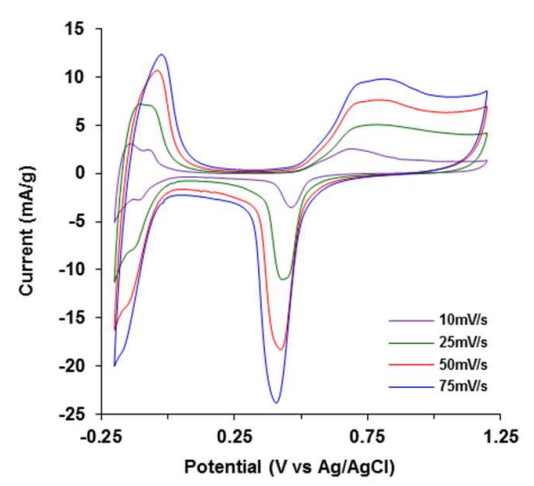

\section{(b)}

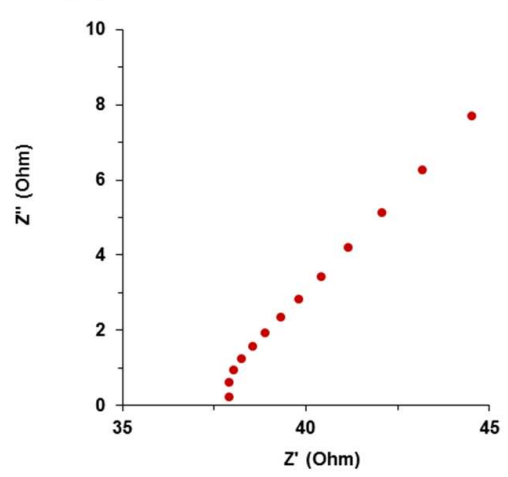

(d)

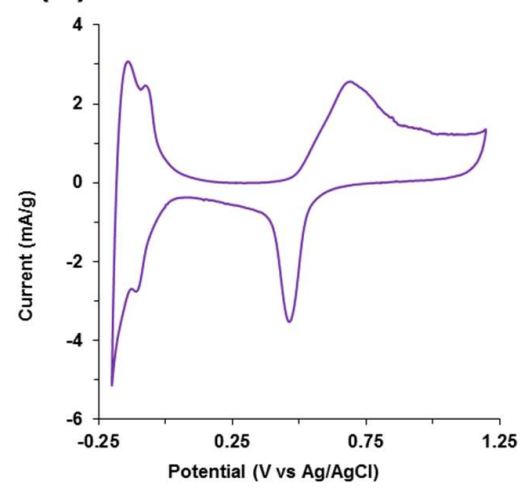

Figure 7. Electrochemical characterization in $0.5 \mathrm{M} \mathrm{H}_{2} \mathrm{SO}_{4}$ of CNF-Pd aerogels prepared from $1000 \mathrm{mM}$ $\operatorname{Pd}\left(\mathrm{NH}_{3}\right)_{4} \mathrm{Cl}_{2}$. (a) electrochemical impedance spectroscopy (EIS) with a $10 \mathrm{mV}$ sine wave was used across frequencies from $140 \mathrm{kHz}$ to $15 \mathrm{mHz}$; (b) high frequency spectra from $140 \mathrm{kHz}$ to $1.3 \mathrm{kHz}$ from (a); (c) cyclic voltammetry (CV) at scan rates of 10, 25, 50, and $75 \mathrm{mV} / \mathrm{s}$; (d) CV scan at $10 \mathrm{mV} / \mathrm{s}$ from (c).

\section{Conclusions}

We have shown here that covalently cross-linked cellulose nanofiber hydrogels serve as a robust biotemplate to synthesize porous, high surface area, electrochemically active CNF-palladium composite aerogels. The CNF hydrogel biotemplate maintains its monolithic shape during all synthesis steps, and the carboxymethyl groups provide electrostatic binding sites for palladium cations and subsequent reduction of nanoparticles. This work demonstrates the ability to control the palladium metal content within a CNF hydrogel, and consequently control the performance characteristics of the material. CNF-palladium composite aerogels demonstrate a synthesis route to potentially use a variety of biological template hydrogels with $\mathrm{pH}$ tunable surface charge with other noble and transition metals compatible with aqueous solution reduction chemistries for a wide range of energy storage, catalysis, and sensing applications.

Supplementary Materials: The following are available online, Figure S1: SEM images of nanofoams prepared from CNF ionic hydrogels, Figure S2: X-ray diffraction spectra for CNF-Pd aerogels synthesized from $\mathrm{Na}_{2} \mathrm{PdCl}_{4}$, 
Figure S3: TGA of aerogels synthesized with $\mathrm{Na}_{2} \mathrm{PdCl}_{4}$, Figure S4: Nitrogen gas adsorption-desorption overlay, and Figure S5: EIS Fitting.

Author Contributions: F.J.B., A.N.M., and E.A.N. conceived and designed the experiments; J.L.P. and M.Y.R. made the samples; F.J.B., A.N.M., E.A.N., J.L.P. and M.Y.R. performed the experiments; F.J.B, A.N.M., E.A.N., and J.K.W. analyzed the data; F.J.B., A.N.M., and L.A.M contributed reagents/materials/analysis tools; F.J.B., A.N.M., and E.A.N. wrote the paper.

Funding: This work was funded by a Faculty Development Research Fund grant from the United States Military Academy. A.N.M. was funded by the National Academy of Sciences through the National Research Council.

Acknowledgments: The authors thank Stephen Bartolucci and Joshua Maurer from Watervliet Arsenal and Benet Laboratories for providing use of their SEM, and Picatinny Arsenal for allowing us to use their BET.

Conflicts of Interest: The authors declare no conflict of interest.

\section{References}

1. Sotiropoulou, S.; Sierra-Sastre, Y.; Mark, S.S.; Batt, C.A. Biotemplated Nanostructured Materials. Chem. Mater. 2008, 20, 821-834. [CrossRef]

2. Bashir, R. BioMEMS: State-of-the-Art in Detection, Opportunities and Prospects. Advanc. Drug Deliv. Rev. 2004, 56, 1565-1586. [CrossRef] [PubMed]

3. Kim, S.; Marelli, B.; Brenckle, M.A.; Mitropoulos, A.N.; Gil, E.-S.; Tsioris, K.; Tao, H.; Kaplan, D.L.; Omenetto, F.G. All-Water-Based Electron-Beam Lithography Using Silk as a Resist. Nat. Nanotechnol. 2014, 9, 306-310. [CrossRef] [PubMed]

4. Cook, G.; Timms, P.L.; Göltner-Spickermann, C. Exact Replication of Biological Structures by Chemical Vapor Deposition of Silica. Angew. Chemie Int. Ed. 2003, 42, 557-559. [CrossRef] [PubMed]

5. Wang, X.; Kim, H.J.; Xu, P.; Matsumoto, A.; Kaplan, D.L. Biomaterial Coatings by Stepwise Deposition of Silk Fibroin. Langmuir 2005, 21, 11335-11341. [CrossRef] [PubMed]

6. Wang, G.; Kundu, D.; Uyama, H. One-Pot Fabrication of Palladium Nanoparticles Captured in Mesoporous Polymeric Monoliths and Their Catalytic Application in C-C Coupling Reactions. J. Colloid Interface Sci. 2015, 451, 184-188. [CrossRef] [PubMed]

7. Cirtiu, C.M.; Dunlop-Brière, A.F.; Moores, A. Cellulose Nanocrystallites as an Efficient Support for Nanoparticles of Palladium: Application for Catalytichydrogenation and Heck Coupling under Mild Conditions. Green Chem. 2011, 13, 288-291. [CrossRef]

8. Jarvis, M. Cellulose Stacks up. Nature. 2003, 426, 611-612. [CrossRef] [PubMed]

9. Yoon, K.; Hsiao, B.S.; Chu, B. Functional Nanofibers for Environmental Applications. J. Mater. Chem. 2008, 18, 5326. [CrossRef]

10. Siró, I.; Plackett, D. Microfibrillated Cellulose and New Nanocomposite Materials: A Review. Cellulose. 2010, 17, 459-494. [CrossRef]

11. Takagi, H.; Asano, A. Effects of Processing Conditions on Flexural Properties of Cellulose Nanofiber Reinforced "green" composites. Compos. Part A Appl. Sci. Manuf. 2008, 39, 685-689. [CrossRef]

12. Dufresne, A. Nanocellulose: A New Ageless Bionanomaterial. Mater. Today 2013, 16, 220-227. [CrossRef]

13. Grishkewich, N.; Mohammed, N.; Tang, J.; Tam, K.C. Recent Advances in the Application of Cellulose Nanocrystals. Curr. Opin. Colloid Interface Sci. 2017, 29, 32-45. [CrossRef]

14. Ramires, E.C.; Dufresne, A. A Review of Cellulose Nanocrystals and Nanocomposites. Tappi J. 2011, 10, 9-16.

15. Wang, J.; Zhang, J.; Han, J. Synthesis of Crystals and Particles by Crystallization and Polymerization in Droplet-Based Microfluidic Devices. Front. Chem. Eng. China 2010, 4, 26-36. [CrossRef]

16. Lin, N.; Dufresne, A. Nanocellulose in Biomedicine: Current Status and Future Prospect. Eur. Polym. J. 2014, 59, 302-325. [CrossRef]

17. Jorfi, M.; Foster, E.J. Recent Advances in Nanocellulose for Biomedical Applications. J. Appl. Polym. Sci. 2015, 132, 41719. [CrossRef]

18. Eyley, S.; Thielemans, W. Surface Modification of Cellulose Nanocrystals. Nanoscale 2014, 6, 7764-7779. [CrossRef] [PubMed]

19. Abdul Khalil, H.P.S.; Davoudpour, Y.; Islam, M.N.; Mustapha, A.; Sudesh, K.; Dungani, R.; Jawaid, M. Production and Modification of Nanofibrillated Cellulose Using Various Mechanical Processes: A Review. Carbohydr. Polym. 2014, 99, 649-665. [CrossRef] [PubMed] 
20. Missoum, K.; Belgacem, M.N.; Bras, J. Nanofibrillated Cellulose Surface Modification: A Review. Materials (Basel). 2013, 6, 1745-1766. [CrossRef] [PubMed]

21. Song, J.; Chen, C.; Zhu, S.; Zhu, M.; Dai, J.; Ray, U.; Li, Y.; Kuang, Y.; Li, Y.; Quispe, N.; et al. Processing Bulk Natural Wood into a High-Performance Structural Material. Nature 2018, 554, 224-228. [CrossRef] [PubMed]

22. Xue, Y.; Mou, Z.; Xiao, H. Nanocellulose as Sustainable Biomass Material: Structure, Properties, Present Status and Future Prospects in Biomedical Applications. Nanoscale 2017, 9, 14758-14781. [CrossRef] [PubMed]

23. Kim, J.H.; Shim, B.S.; Kim, H.S.; Lee, Y.J.; Min, S.K.; Jang, D.; Abas, Z.; Kim, J. Review of Nanocellulose for Sustainable Future Materials. Int. J. Precis. Eng. Manuf.-Green Technol. 2015, 2, 197-213. [CrossRef]

24. Abitbol, T.; Rivkin, A.; Cao, Y.; Nevo, Y.; Abraham, E.; Ben-Shalom, T.; Lapidot, S.; Shoseyov, O. Nanocellulose, a Tiny Fiber with Huge Applications. Curr. Opin. Biotechnol. 2016, 39, 76-88. [CrossRef] [PubMed]

25. Nechyporchuk, O.; Belgacem, M.N.; Bras, J. Production of Cellulose Nanofibrils: A Review of Recent Advances. Ind. Crops Prod. 2016, 93, 2-25. [CrossRef]

26. Fischer, F.; Rigacci, A.; Pirard, R.; Berthon-Fabry, S.; Achard, P. Cellulose-Based Aerogels. Polym. (Guildf). 2006, 47, 7636-7645. [CrossRef]

27. Jin, H.; Nishiyama, Y.; Wada, M.; Kuga, S. Nanofibrillar Cellulose Aerogels. Colloids Surfaces A Physicochem. Eng. Asp. 2004, 240, 63-67. [CrossRef]

28. Sehaqui, H.; Zhou, Q.; Berglund, L.A. High-Porosity Aerogels of High Specific Surface Area Prepared from Nanofibrillated Cellulose (NFC). Compos. Sci. Technol. 2011, 71, 1593-1599. [CrossRef]

29. Ifuku, S.; Nogi, M.; Abe, K.; Handa, K.; Nakatsubo, F.; Yano, H. Surface Modification of Bacterial Cellulose Nanofibers for Property Enhancement of Optically Transparent Composites: Dependence on Acetyl-Group DS. Biomacromolecules 2007, 8, 1973-1978. [CrossRef] [PubMed]

30. Xu, Y.; Wang, T.; He, Z.; Zhong, A.; Huang, K. Carboxyl-Containing Microporous Organic Nanotube Networks as a Platform for Pd Catalysts. RSC Adv. 2016, 6, 39933-39939. [CrossRef]

31. Wu, X.; Shi, Z.; Fu, S.; Chen, J.; Berry, R.M.; Tam, K.C. Strategy for Synthesizing Porous Cellulose Nanocrystal Supported Metal Nanocatalysts. ACS Sustain. Chem. Eng. 2016, 4, 5929-5935. [CrossRef]

32. Li, Y.; Xu, L.; Xu, B.; Mao, Z.; Xu, H.; Zhong, Y.; Zhang, L.; Wang, B.; Sui, X. Cellulose Sponge Supported Palladium Nanoparticles as Recyclable Cross-Coupling Catalysts. ACS Appl. Mater. Interfaces 2017, 9, 17155-17162. [CrossRef] [PubMed]

33. Cai, J.; Kimura, S.; Wada, M.; Kuga, S. Nanoporous Cellulose as Metal Nanoparticles Support. Biomacromolecules 2009, 10, 87-94. [CrossRef] [PubMed]

34. Dong, B.H.; Hinestroza, J.P. Metal Nanoparticles on Natural Cellulose Fibers: Electrostatic Assembly and in Situ Synthesis. ACS Appl. Mater. Interfaces 2009, 1, 797-803. [CrossRef] [PubMed]

35. Song, L.T.; Wu, Z.Y.; Liang, H.W.; Zhou, F.; Yu, Z.Y.; Xu, L.; Pan, Z.; Yu, S.H. Macroscopic-Scale Synthesis of Nitrogen-Doped Carbon Nanofiber Aerogels by Template-Directed Hydrothermal Carbonization of Nitrogen-Containing Carbohydrates. Nano Energy 2016, 19, 117-127. [CrossRef]

36. Ingale, S.V.; Sastry, P.U.; Wagh, P.B.; Tripathi, A.K.; Rao, R.; Tewari, R.; Rao, P.T.; Patel, R.P.; Tyagi, A.K.; Gupta, S.C. Synthesis and Micro Structural Investigations of Titania-Silica Nano Composite Aerogels. Mater. Chem. Phys. 2012, 135, 497-502. [CrossRef]

37. Zielasek, V.; Jürgens, B.; Schulz, C.; Biener, J.; Biener, M.M.; Hamza, A.V.; Bäumer, M. Gold Catalysts: Nanoporous Gold Foams. Angew. Chemie-Int. Ed. 2006, 45, 8241-8244. [CrossRef] [PubMed]

38. Jung, S.M.; Jung, H.Y.; Fang, W.; Dresselhaus, M.S.; Kong, J. A Facile Methodology for the Production of in Situ Inorganic Nanowire Hydrogels/aerogels. Nano Lett. 2014, 14, 1810-1817. [CrossRef] [PubMed]

39. Burpo, F.J.; Nagelli, E.A.; Morris, L.A.; McClure, J.P.; Ryu, M.Y.; Palmer, J.L. Direct Solution-Based Reduction Synthesis of Au, Pd, and Pt Aerogels. J. Mater. Res. 2017, 32, 4153-4165. [CrossRef]

40. Gopiraman, M.; Bang, H.; Yuan, G.; Yin, C.; Song, K.H.; Lee, J.S.; Chung, I.M.; Karvembu, R.; Kim, I.S. Noble Metal/functionalized Cellulose Nanofiber Composites for Catalytic Applications. Carbohydr. Polym. 2015, 132, 554-564. [CrossRef] [PubMed]

41. Joo, S.H.; Park, J.Y.; Renzas, J.R.; Butcher, D.R.; Huang, W.; Somorjai, G.A. Size Effect of Ruthenium Nanoparticles in Catalytic Carbon Monoxide Oxidation. Nano Lett. 2010, 10, 2709-2713. [CrossRef] [PubMed]

42. Ho, C.M.; Yu, W.Y.; Che, C.M. Ruthenium Nanoparticles Supported on Hydroxyapatite as an Efficient and Recyclable Catalyst for Cis-Dihydroxylation and Oxidative Cleavage of Alkenes. Angew. Chemie-Int. Ed. 2004, 43, 3303-3307. [CrossRef] [PubMed] 
43. Nyczyk, A.; Sniechota, A.; Adamczyk, A.; Bernasik, A.; Turek, W.; Hasik, M. Investigations of Polyaniline-Platinum Composites Prepared by Sodium Borohydride Reduction. Eur. Polym. J. 2008, 44, 1594-1602. [CrossRef]

44. Williams, J.R.; Clifford, A.A.; al-Saidi, S.H.R. Supercritical Fluids and Their Applications in Biotechnology and Related Areas. Mol. Biotechnol. 2002, 22, 263-286. [CrossRef]

45. Cooper, A. Clean Polymer Synthesis and Processing Using Supercritical Carbon Dioxide. Green Chem. 1999, 1, G167-G168. [CrossRef]

46. Sing, K.S.W. Reporting Physisorption Data for Gas/solid Systems with Special Reference to the Determination of Surface Area and Porosity (Recommendations 1984). Pure Appl. Chem. 1985, 57, 603-619. [CrossRef]

47. Brunauer, S.; Emmett, P.H.; Teller, E. Adsorption of Gases in Multimolecular Layers. J. Am. Chem. Soc. 1938, 60, 309-319. [CrossRef]

48. Barrett, E.P.; Joyner, L.G.; Halenda, P.P. The Determination of Pore Volume and Area Distributions in Porous Substances. I. Computations from Nitrogen Isotherms. J. Am. Chem. Soc. 1951, 73, 373-380. [CrossRef]

49. Craver, C.D.; Charles, E.; Carraher, J.; Boffa, L.S. Applied Polymer Science: 21st Century; Elsevier Science: Amsterdam, Netherlands, 2000; pp. 305-316.

50. Sannino, A.; Pappadà, S.; Madaghiele, M.; Maffezzoli, A.; Ambrosio, L.; Nicolais, L. Crosslinking of Cellulose Derivatives and Hyaluronic Acid with Water-Soluble Carbodiimide. Polym. (Guildf). 2005, 46, 11206-11212. [CrossRef]

51. Jewell, L.L.; Davis, B.H. Review of Absorption and Adsorption in the Hydrogen-Palladium System. Appl. Catalysis A: Gen. 2006, 310, 1-15. [CrossRef]

52. Borsoi, C.; Zimmernnam, M.V.G.; Zattera, A.J.; Santana, R.M.C.; Ferreira, C.A. Thermal Degradation Behavior of Cellulose Nanofibers and Nanowhiskers. J. Therm. Anal. Calorim. 2016, 126, 1867-1878. [CrossRef]

53. Bisquert, J. Infuence of the boundaries in the impedance of porous film electrodes. Phys. Chem. Chem. Phys. 2000, 2, 4185-4192. [CrossRef]

54. Bisquert, J. Theory of the Impedance of Electron Diffusion and Recombination in a Thin Layer. J. Phys. Chem. B 2002, 106, 325-333. [CrossRef]

55. Bisquert, J.; Garcia-Belmonte, G.; Bueno, P.; Longo, E.; Bulhoes, L.O.S. Impedance of constant phase element (CPE)-blocked diffusion in film electrodes. J. Electroanal. Chem. 1998, 452, 229-234. [CrossRef]

Sample Availability: Samples of the CNF-Pd aerogels are available from the authors.

(C) 2018 by the authors. Licensee MDPI, Basel, Switzerland. This article is an open access article distributed under the terms and conditions of the Creative Commons Attribution (CC BY) license (http:// creativecommons.org/licenses/by/4.0/). 